\title{
Blood salvage, proper choice for tumor patients?
}

\author{
Weixin Zhou, Yuanshuai Huang* \\ Department of Transfusion of Affiliated Hospital, Southwest Medical University, Luzhou, Sichuan 646000, China
}

\begin{abstract}
Blood transfusion is frequently used in tumor patients. However, allogeneic blood transfusion have been claimed to be associated with an increased risk of negative outcomes, including transfusion reactions, fever, virus transmission, and alloimmunization. Other risks of homologous transfusion specific to the tumor patients are the potential deleterious effects on the recurrence of tumor and indefinite overall survival. On the contrary, autologous blood transfusion offers survival advantages to tumor patients and has been shown to minimize the occurrence of many detrimental allogeneic blood associated effects and complications. It also reduces the volume of banked blood needed and improves the prognosis of patients. However, the quality of salvaged blood is still a matter of debate, because it may contain tumor cells which are associated with potential detrimental effects such as metastasis. So, an advanced technology is needed to remove such contaminants to make autologous blood transfusion safer.
\end{abstract}

Keywords: blood salvage, homologous transfusion, salvaged blood, irradiation, leukocyte depletion filter

Transfusion of red blood cells can quickly enhance the oxygen carrying capacity and increase the volume of blood. However, it is also associated with many inherent risks and adverse effects, including transfusion reactions, virus transmission, and alloimmunization. Other complications of homologous transfusion such as acute hemolysis, and transfusion-related acute lung injury also lead to serious consequences ${ }^{[1]}$. Additionally, some researchers have reported increased infection rates and mortality, and delayed wound healing related to the high homologous transfusion frequency ${ }^{[2]}$. With the goal of minimizing exposure to allogeneic blood to avoid these harmful effects, the volume of red blood cell (RBC) transfusion should be limited $^{[3]}$. These adverse reactions may be related to suppression of cytotoxic T-cells, natural killer cells, and activation of $\mathrm{T}$-suppressor cells ${ }^{[4]}$. Particularly, in tumor patients who need transfusion, multiple reports

\footnotetext{
*Correspondence to: Yuanshuai Huang, PhD, Department of Transfusion of Affiliated Hospital, Southwest Medical University, Luzhou, Sichuan 646000, China. TEL: 86-15808307577; FAX: 86-8303165740; E-mail: hys@live.cn.
}

indicated that allogeneic transfusion increased the rates of recurrence after tumorectomy ${ }^{[5-7]}$, and the mechanism is undetermined. Therefore, autologous transfusion was recommended for cancer patients. However, this is still controversial for the potential danger of tumor cells contaminated blood containing, which might increase the risks of distant metastasis of tumor.

\section{The deficiency of allogeneic blood transfu- sion with tumor patients}

In addition to the disadventages mentioned above, allogeneic blood transfusion may induce the metastasis and relapse of tumor. Tartter PI and colleagues ${ }^{[8]}$ first reported that perioperative allogeneic blood transfusion (ABT) accelerated the recurrence or metastasis of lung cancer. Subsequently, Weitz $\mathbf{J}$ and colleagues $^{[9]}$ reported that allogeneic blood transfusion had a negative effect on the recurrence of proximal gastric and gastroesophageal junction cancer. Abel EJ et $a l^{[10]}$ studied the idea that intraoperative blood transfusion may increase the recurrent risk and mortality of bladder cancer. Kim $\mathrm{JK}^{[6]}$ evaluated the association between perioperative blood transfusion 
(PBT) and the biochemical recurrence-free survival (BRFS), cancer-specific survival (CSS), and overall survival (OS) after radical prostatectomy in patients with prostate cancer, they found that allogeneic PBT was significantly related with decreased BRFS, CSS, and OS. Linder BJ and Morgan $\mathrm{TM}^{[11,12]}$ also demonstrated the association of allogeneic blood transfusion with the recurrence rates and survival outcomes in urological cancers. The mechanism of recurrence is as yet indefinable, but it has been hypothesized to be immune-mediated, thereby compromising the immunologic competence of the host and allowing residual tumor cells to develop themselves, especially in tumor patients with suppressed immunity ${ }^{[13]}$. The side effects of homologous transfusion have been identified by so many reports mentioned above, while autologous transfusion technology may provide a safer alternative to the tumor patients as compared to homologous transfusion.

\section{Is blood salvage safe for tumor patients?}

Autotransfusion is a way to avoid or at least minimize patients' exposure to allogeneic blood. Although a disposable system is needed for autotransfusion, it is more cost effective than a single unit of donated red cells ${ }^{[14]}$. In 1874, the first successful autotransfusion was completed by a German physician, Hueter, who transfused $350 \mathrm{~mL}$ of autologous blood into the left tibial artery of a patient with frost-gangrene on both feet. The left foot was salvaged, whereas the right one was not. Later, in 1883, William Halsted demonstrated that autotransfusion did not increase mortality. He described a case in which he removed half a liter of blood from a victim of carbon monoxide poisoning, defibrinated it, strained it, and returned about a quarter liter of the blood back to the patient, who then recovered $^{[15]}$. So far, autotransfusion has a long history of more than one hundred years. Nowadays autotransfusion can be categorized into three types according to different methods: hemodilution autotransfusion, blood salvage transfusion and predeposit autotransfusion. For tumor patients during surgery, blood salvage transfusion is the most common approach. However, is it safe for tumor patients?

Since 1986, there have been 10 studies published, and more than 400 tumor patients received blood salvage during resection of multiple tumors including the prostate cancer ${ }^{[16-18]}$, gynecologic oncology ${ }^{[19,20]}$, tumors of urologic system ${ }^{[21,22]}$, metastatic spinal tumor ${ }^{[23]}$, liver cancer ${ }^{[24,25]}$. These reports provided no support for the theoretical risk: (1)the salvaged blood contains malignant cells; (2) therefore may subse- quently constitute widespread metastasis. As early as 2005, Takemura $\mathrm{M}^{[26]}$ compared the outcomes of patients with T3 and T4 stage oesophageal cancer who received autologous blood with those who received allogeneic blood, and latter showed an improved survival oesophagectomy. Higher natural killer cell activity was demonstrated in the autologous group $(P<0.05)$ and recommended a possible mechanism of improved survival. Then Neider AM and co-workers ${ }^{[17]}$ found no difference on biochemical recurrence between the patients receiving cell salvaged blood and those who received no blood in a five-year followup, by retrospectively reviewing 1,038 patients undergoing radical prostatectomy from 1992 to 2003. More recently, the same group reported on long-term survival in a group of 378 patients undergoing radical prostatectomy from 1992 to 2005 and found that overall survival had no significant difference between those who received cell salvaged blood and those who did not ${ }^{[27]}$. In Raval JS's study in $2012^{[28]}$, they introduced "intraoperative cell salvage in radical prostatectomy", their findings supported the previous opinion that intraoperative cell salvage (ICS) did not increase probability of biochemical failure, disease dissemination, or mortality within approximately 5 years of follow-up. Engle $\mathrm{DB}^{[4]}$ also certified that autologous blood transfusion during radical hysterectomy for cervical cancer appeared effective and safe. The most comprehensive study of intraoperative blood salvage autotransfusion (IBSA) systems in cancer surgery was conducted as a meta-analysis including 10 published studies of 2,326 patients with liver, cervical, prostate, or gastrointestinal cancer, the results demonstrated that IBSA did not increase the risk of tumor recurrence or metastasis $^{[29]}$. In 2013, Akbulut $\mathrm{S}^{[2]}$ proved that continuous autotransfusion system (CATS) during liver transplantation of hepatocellular carcinoma(HCC) patients was safe and did not influence the recurrent rate of the patients. Kim JM ${ }^{[30]}$ also indicated that blood salvage did not increase the recurrence of the tumor. The findings of Araujo RL ${ }^{[31]}$ were also consistent with them. In 2016, Han $\mathrm{S}^{[32]}$ also reported that HCC patients who were reinfused salvaged autologous red blood cells during liver transplantation shown no significantly difference in overall recurrence compared with non-autotransfusion group. Particularly, in April 2008, a recommendation from the National Institute for Health and Clinical Excellence (NICE) approved the use of autologous blood transfusion in cancer surgery, specifically prostatectomy and cystectomy ${ }^{[33]}$. Additionally, ICS was so well established in other surgical specialties, that NICE endorsed its usage in urological cancer in $2012^{[14]}$. Not only can blood 
salvage avoid the shortcomings of allogeneic blood transfusion mentioned above, it can also markedly reduce the probability of tumor recurrence and mortality, and save valuable blood resources. However, all the studies mentioned above were retrospective, so the evidence is still insufficient, and it is necessary to reevaluate the benefits of blood salvage during oncologic surgery.

\section{The potential risk of blood salvage}

Commonly, blood salvage is avoided in cancer surgery due to a fear of causing disseminated metastasis by facilitating cancer cells into the shed blood and reinfusing them subsequently into circulation. Based on this understanding, it would seem like a prudent idea to avoid blood salvage in tumor patients, because malignant cells are associated with potential metastasis or cancer recurrence.

In 1975, a case report was published where a patient had blood salvage utilized during a pneumonectomy. Four weeks later, the patient died. The authors concluded that the reinfusion of these cells was responsible for the patient's early demise because of the malignant cells detected in the salvaged blood ${ }^{[34]}$. This is the first case demonstrated the connection between autotransfusion and tumor metastasis, and it has been reported that a majority of the blood samples collected in the field of tumor surgery also contain tumor cells ${ }^{[35]}$. For this reason, the theoretical concern has been highly recommended in the past by the American Medical Association Council on Scientific Affairs against blood salvage during cancer surgery ${ }^{[36]}$. However, these contraindications are not supported by any evidence, and are now being revised for the benefit of cell salvage systems to remove such contaminants in many recent studies.

\section{Is there any way to make salvaged blood safer?}

There is no published data supporting the contradictions, and the case series we cited seem to show that extensive metastasis did not arise shortly after blood salvage. However, we cannot guarantee blood salvage doesn't accelerate the metastasis and cancer recurrence. If we remove the residual malignant cells, should blood salvage be safer? Leukoreduction filters have been advocated to remove tumor cells during cancer surgery, such as urologic surgery ${ }^{[36]}$ and pulmonary surgery ${ }^{[37]}$, these studies have all concluded that leukoreduction filters were highly effective in removing tumor cell contamination.

Recently, Kumar N and co-workers ${ }^{[38]}$ evaluated the feasibility of intraoperative cell salvage (IOCS) in combination with a leukocyte depletion filter (LDF) in patients during metastatic spine tumor surgery (MSTS) by using flow cytometry. The analysis of the flow cytometry showed that tumor cells existed in 8 out of 11 unfiltered salvaged patients' blood. In the filtered salvaged blood, the tumor cell count was zero in the majority of samples $(8 / 11)$, whereas there were a few tumor cells in three patients' filtered samples. Their study showed that IOCS-LDF treated blood in MSTS was safe for transfusion. Mei K and Catling $S^{[39,40]}$ both showed that LDF could also remove tumor cells from the salvaged blood. Interestingly, Hansen ${ }^{[41]}$ suggested that gamma irradiation could make a 12-log reduction which was superior to leukoreduction filters (3- to 4-log reduction). In order to test it, tumor cells from established cell lines or from solid tumors were mixed with red blood cells from volunteer blood donations, and were treated by irradiation with $50 \mathrm{~Gy}$. The results showed that the method of intraoperative blood salvage during tumor surgery with gamma irradiation was feasible and efficient. A more recent study by Gong $\mathrm{M}^{[42]}$ estimated the efficiency of ${ }^{137} \mathrm{Cs}$ gamma-ray irradiation in removing gastrocarcinoma (SGC7901), human hepatocarcinoma (HepG2), and colonic carcinoma (SW620) cell lines in vitro and in vivo. They showed that irradiation of ${ }^{137} \mathrm{Cs}$ significantly inhibited the viability, colony formation and DNA synthesis of HepG2, SGC7901 and SW620 cells, and cell death increased after exposure to ${ }^{137} \mathrm{Cs}$ gamma rays, in addition, none of these three cell lines treated with 50 Gy irradiation developed xenograft tumors. LDF and gamma irradiation are most commonly used strategies to remove tumor cell contamination, which make blood salvage transfusion safer.

In tumor patients, many adverse effects of homologous transfusion have been identified, while autologous transfusion could be a safer alternative. Blood salvage, of course, is still a tough problem during cancer treatment. During this processing, the key point is how to remove the tumor cells from salvaged blood, and the ultimate aim is to make blood salvage the ideal choice for tumor patients. Beyond LDF and gamma irradiation, we expect novel advanced technology to make blood salvage of tumor patients safer.

\section{References}

[1] Robich MP, Koch CG, Johnston DR, et al. Trends in blood utilization in United States cardiac surgical patients. Transfusion, 2015;55(4):805-14.

[2] Akbulut S, Kayaalp C, Yilmaz M, et al. Effect of autotransfusion system on tumor recurrence and survival in hepatocellular carcinoma patients. World J Gastroenterol, 2013;19(10):1625-31. 
[3] Practice guidelines for perioperative blood management. an updated report by the American Society of Anesthesiologists Task Force on Perioperative Blood Management ${ }^{*}$. Anesthesiology, 2015;122(2):241-75.

[4] Engle DB, Connor JP, Morris PC, et al. Intraoperative autologous blood transfusion use during radical hysterectomy for cervical cancer: long-term followup of a prospective trial. Arch Gynecol Obstet, 2012;286(3):717-21.

[5] Meng J, Lu XB, Tang YX, et al. Effects of allogeneic blood transfusion in patients with stage II colon cancer.

Asian Pac J Cancer Prev, 2013;14(1):347-50.

[6] Kim JK, Kim HS, Park J, et al. Perioperative blood transfusion as a significant predictor of biochemical recurrence and survival after radical prostatectomy in patients with prostate cancer. PLoS One, 2016;11(5):e0154918.

[7] Kanda M, Kobayashi D, Tanaka C, et al. Adverse prognostic impact of perioperative allogeneic transfusion on patients with stage II / III gastric cancer. Gastric Cancer, 2016;19(1):255-63.

[8] Tartter PI, Burrows L, Kirschner P. Perioperative blood transfusion adversely affects prognosis after resection of Stage I (subset N0) non-oat cell lung cancer. J Thorac Cardiovasc Surg, 1984;88(5 Pt 1):659-62.

[9] Weitz J, D’Angelica M, Gonen M, et al. Interaction of splenectomy and perioperative blood transfusions on prognosis of patients with proximal gastric and gastroesophageal junction cancer. J Clin Oncol, 2003;21(24):4597-603.

[10] Abel EJ, Linder BJ, Bauman TM, et al. Perioperative blood transfusion and radical cystectomy: does timing of transfusion affect bladder cancer mortality? Eur Urol, 2014;66(6):1139-47.

[11] Linder BJ, Thompson RH, Leibovich BC, et al. The impact of perioperative blood transfusion on survival after nephrectomy for non-metastatic renal cell carcinoma (RCC). BJU Int, 2014;114(3):368-74.

[12] Morgan TM, Barocas DA, Chang SS, et al. The relationship between perioperative blood transfusion and overall mortality in patients undergoing radical cystectomy for bladder cancer. Urol Oncol, 2013;31(6):871-7.

[13] Hirano T, Yamanaka J, Iimuro Y, et al. Long-term safety of autotransfusion during hepatectomy for hepatocellular carcinoma. Surg Today, 2005;35(12):1042-6.

[14] Nusrath MA, Edge CJ, Ahmed-Nusrath A. Intraoperative red cell salvage in head and neck surgery. Br J Oral Maxillofac Surg, 2012;50(3):272-4.

[15] Konig G, Waters JH. Washing and filtering of cellsalvaged blood - does it make autotransfusion safer? Transfus Altern Transfus Med, 2012;12(3-4):78-87.

[16] Davis M, Sofer M, Gomez-Marin O, et al. The use of cell salvage during radical retropubic prostatectomy: does it influence cancer recurrence? BJU Int, 2003;91(6):474-6.

[17] Nieder AM, Carmack AJ, Sved PD, et al. Intraoperative cell salvage during radical prostatectomy is not associ- ated with greater biochemical recurrence rate. Urology, 2005;65(4):730-4.

[18] Stoffel JT, Topjian L, Libertino JA. Analysis of peripheral blood for prostate cells after autologous transfusion given during radical prostatectomy. BJU Int, 2005;96(3):313-5.

[19] Nagarsheth NP, Sharma T, Shander A, et al. Blood salvage use in gynecologic oncology. Transfusion, 2009;49(10):2048-53.

[20] Mirhashemi R, Averette HE, Deepika K, et al. The impact of intraoperative autologous blood transfusion during type III radical hysterectomy for early-stage cervical cancer. Am J Obstet Gynecol, 1999;181(6):1310-5; discussion 1315-6.

[21] Monk TG, Goodnough LT. Blood conservation strategies to minimize allogeneic blood use in urologic surgery. Am J Surg, 1995;170(6A Suppl):69s-73s.

[22] Hart OJ, 3rd, Klimberg IW, Wajsman Z, et al. Intraoperative autotransfusion in radical cystectomy for carcinoma of the bladder. Surg Gynecol Obstet, 1989;168(4):3026.

[23] Gakhar H, Bagouri M, Bommireddy R, et al. Role of intraoperative red cell salvage and autologus transfusion in metastatic spine surgery: a pilot study and review of literature. Asian Spine J, 2013;7(3):167-72.

[24] Phillips SD, Maguire D, Deshpande R, et al. A prospective study investigating the cost effectiveness of intraoperative blood salvage during liver transplantation. Transplantation, 2006;81(4):536-40.

[25] Muscari F, Suc B, Vigouroux D, et al. Blood salvage autotransfusion during transplantation for hepatocarcinoma: does it increase the risk of neoplastic recurrence? Transpl Int, 2005;18(11):1236-9.

[26] Takemura M, Osugi H, Higashino M, et al. Effect of substituting allogenic blood transfusion with autologous blood transfusion on outcomes after radical oesophagectomy for cancer. Ann Thorac Cardiovasc Surg, 2005;11(5):293-300.

[27] Nieder AM, Manoharan M, Yang Y, et al. Intraoperative cell salvage during radical cystectomy does not affect long-term survival. Urology, 2007;69(5):881-4.

[28] Raval JS, Nelson JB, Woldemichael E, et al. Intraoperative cell salvage in radical prostatectomy does not appear to increase long-term biochemical recurrence, metastases, or mortality. Transfusion, 2012;52(12):2590-3.

[29] Waters JH, Yazer M, Chen YF, et al. Blood salvage and cancer surgery: a meta-analysis of available studies. Transfusion, 2012;52(10):2167-73.

[30] Kim JM, Kim GS, Joh JW, et al. Long-term results for living donor liver transplant recipients with hepatocellular carcinoma using intraoperative blood salvage with leukocyte depletion filter. Transpl Int, 2013;26(1):84-9.

[31] Araujo RL, Pantanali CA, Haddad L, et al. Does autologous blood transfusion during liver transplantation for hepatocellular carcinoma increase risk of recurrence? World J Gastrointest Surg, 2016;8(2):161-8.

[32] Han S, Kim G, Ko JS, et al. Safety of the use of 
blood salvage and autotransfusion during liver transplantation for hepatocellular carcinoma. Ann Surg, 2016;264(2):339-43.

[33] Bouras I, Mingo O. Should cell salvage be used in oncological surgery? Br J Hosp Med (Lond), 2010;71(1):57.

[34] Yaw PB, Sentany M, Link WJ, et al. Tumor cells carried through autotransfusion. Contraindication to intraoperative blood recovery? JAMA, 1975;231(5):490-1.

[35] Oefelein MG, Kaul K, Herz B, et al. Molecular detection of prostate epithelial cells from the surgical field and peripheral circulation during radical prostatectomy. J Urol, 1996;155(1):238-42.

[36] Edelman MJ, Potter P, Mahaffey KG, et al. The potential for reintroduction of tumor cells during intraoperative blood salvage: reduction of risk with use of the RC-400 leukocyte depletion filter. Urology, 1996;47(2):179-81.

[37] Perseghin P, Vigano M, Rocco G, et al. Effectiveness of leukocyte filters in reducing tumor cell contamination after intraoperative blood salvage in lung cancer patients. Vox Sang, 1997;72(4):221-4.
[38] Kumar N, Lam R, Zaw AS, et al. Flow cytometric evaluation of the safety of intraoperative salvaged blood filtered with leucocyte depletion filter in spine tumour surgery. Ann Surg Oncol, 2014;21(13):4330-5.

[39] Mei K, Du L, Yan M, et al. Modified leukocyte filter removes tumor cells from the salvaged blood. PLoS One, 2015;10(6):e0130864.

[40] Catling S, Williams S, Freites O, et al. Use of a leucocyte filter to remove tumour cells from intra-operative cell salvage blood. Anaesthesia, 2008;63(12):1332-8.

[41] Hansen E, Altmeppen J, Kutz N, et al. Experimental principles and general practice of intraoperative autotransfusion with blood irradiation in tumor operation. Beitr Infusionsther Transfusionsmed,1996;33:184-90.

[42] Gong M, Yang JT, Liu YQ, et al. Irradiation can selectively kill tumor cells while preserving erythrocyte viability in a co-culture system. PLoS One, 2015;10(5):e0127181.

(Received 22 February 2017, Revised 23 April 2017, Accepted 09 May 2017) 


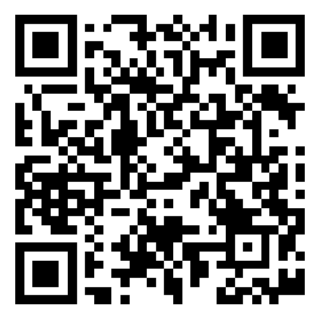

Asia-Pacific Journal

of Blood Types and Genes 